\title{
The independent audio describer is dead: Long live audio description!
}

(D) Louise Fryer ${ }^{\boxplus}$

University College London

Citation: Fryer, L., (2018) The Independent Audio Describer is Dead: Long Live Audio Description! Journal of Audiovisual Translation, 1(1), 170-186.

Editor(s): A. Jankowska \& P. RomeroFresco

Received: January 22, 2018

Accepted: June 30, 2018

Published: November 15, 2018

Funding: This research was supported by the Erasmus+ Programme of the European Union: Project name ADLAB PRO; Project number: 2016-1-IT02KA203-024311.

Copyright: (C2018 Fryer. This is an open access article distributed under the terms of the Creative Commons Attribution License. This allows for unrestricted use, distribution, and reproduction in any medium, provided the original author and source are credited.

\section{Abstract}

Traditional audio description (AD) is giving way to integrated audio description in which media accessibility is no longer an add-on but built in from the start in collaboration with the artistic team. As directors and producers take a greater interest in making their work accessible to audience members with a sensory impairment, how are the power dynamics altered between the stakeholders? The idea of abusive forms of translation advanced by Lewis (1985) and Nornes (1999) is reconsidered, together with the sanctity of the source text (ST). Also assessed is the impact on the role and hence the training needs of the professional audio describer. Using data from research projects developed by Extant, the UK's leading professional performing arts company of visually impaired people, and from the European research project ADLAB PRO, this paper concludes that a describer's skills and competences are still required even with the evolution of integrated $A D$.

Key words: media accessibility, audio description, visual impairment, blindness, describer

\louise@utopians.co.uk; https://orcid.org/0000-0003-0302-8503 


\section{Introduction}

In an era of accessible filmmaking (AFM) and integrated audio description (IAD), is the role of an independent access interpreter outdated? In what way do a describer's skills need to change to reflect the shifting $A D$ environment and how does that affect describer training? This article seeks to answer these questions in the context of ADLAB PRO, a three-year research project financed by the European Union under the Erasmus+ Programme Key Action 2 - Strategic Partnerships. ADLAB $P R O$ is charged with defining the profile of the audio description professional and outlining describer competences in order to create a course and training materials for producing more of these specialists in the future. This article also draws on two research projects organised by Extant which is the UK's leading professional performing arts company of visually impaired people. Although the focus of this article is on Live AD (principally theatre), aspects of subtitling and screen $A D$ are briefly considered.

\subsection{Extant's Research Projects}

The first project called Enhance was based around Extant's tour of the play The Chairs (Ionesco, 1958)

The tour programme was delivered with venue partners in Manchester and Birmingham and included supported attendance and development workshops, to encourage participation by visually impaired audiences, and a series of staff development workshops, to support the delivery of an improved experience for visually impaired audiences and artists (Fortnum \& Hall, 2016, p. 2).

The mainstay of the Enhance programme was support for the companies to develop and deliver audiointroductions and touch tours for six productions, reflecting multiple genres of live performance from puppetry to opera. The second project The Integrated Access Inquiry (Cavallo \& Fryer, 2018) comprised qualitative interviews with 20 theatremakers representing 15 companies across the UK with experience of making their performances accessible to all, and responses from a small focus group of AD users.

\section{Accessibility}

Greco (2016, p. 23) defines media accessibility (MA) as "the research area dealing with theories, practices, technologies and instruments that provide access to media products and environments for people who cannot, or cannot properly, access content in its original form." Issue could be taken with the word "properly" as it carries with it an implication that there is but one normative interpretation. This would seem to lie at the heart of objections to AD as it is currently practiced, which Udo \& Fels (2009) call conventional but here is termed traditional AD (TAD). Discussing their creative approach to Shakespeare's Hamlet in which the director and describer 
worked together to produce an $A D$ in iambic pentameter, spoken by the character Horatio, Udo \& Fels suggest "A conventional audio description would have taken a more objective, less interpretative approach, relaying factual information about the set, costumes, and characters' actions" (2009, p.8). Despite calls to the contrary (Fryer \& Freeman, 2014; Ramos, 2015) it would seem that TAD is still more intent on "providing visual information than catering to the feel of the scene." (Udo \& Fels, 2009, p. 8). Actor, AD user and researcher, Amelia Cavallo (2015) calls this approach occularcentric and it could be argued that a practice designed to be inclusive, becomes exclusive, by presenting information from a sighted viewpoint. This echoes what Hannah Thompson (2015) calls a problematic irony that "AD is designed to help give blind users independence, yet blind [people] are reliant on choices made by sighted describers" $(2015$, para 8$)$.

\subsection{Traditional $A D$}

Traditional $A D$ is typified by five characteristics: it is exclusive; neutral; non-auteur; third-party and post hoc. As such, TAD anchors one extreme of a theoretical spectrum with integrated $A D$ at the other end of it and is unlikely to reflect $A D$ as it is practiced in the real world. Instead it captures $A D$ as it is perceived by theatre makers and by some AD users (Cavallo \& Fryer, 2018; Lopez, Kearney \& Hofstadter, 2018).

Addressing these characteristics in turn: TAD is exclusive in the sense that it has to be listened to via a headset and is therefore not available to the whole audience. This contravenes one of the principles of Universal Design (UD), that a product should "be useable by all people, to the greatest extent possible, without the need for adaptation or specialized design" (Connell et al., 1997)'; TAD urges describers to adopt a neutral approach to word choice and delivery that some users find dull, as one partially sighted AD user expressed it: "Literal description is too boring. I don't like boring voices, so I need emotional connection as well" (Cavallo \& Fryer, 2018, p. 21). TAD is independent in the sense that decisions about content (content selection and the choice of words to describe it) are taken by the describers in collaboration with each other, rather than with members of the artistic team (Naraine, Whitfield \& Fels, 2018). When the process is explained, doubts have been raised in users' minds as to the reliability of this third-party source of information (Lopez, Kearney \& Hofstadter, 2018). The use of external, independent describers has led to frustration on the part of some directors. Artistic director of UK disabled theatre company Graeae, Jenny Sealey objects to "some person coming in, watching the show, writing a script, and coming back and doing it." She asks, "Where was their real understanding of the visceral process of making that theatre?" (Cavallo \& Fryer, 2018, p. 45). It is an approach that is evidently non-auteur. It is also post-hoc, created after the event. In addition, TAD is perceived to be rule bound even though guidelines largely refer to screen $A D$ rather than the $A D$ of live events (Whitfield \& Fels, 2013). The ADLAB guidelines (Remael, Reviers \& Vercauteren, 2015, 3.4.1) devote a brief section to the description of theatre, but when it comes to scripting, these largely refer to advice for screen $A D$. The guidelines advocate a limited amount of collaboration yet fall short of condoning $A D$ 
as an artistic process, as advocated by theatre makers such as Amanda Redvers Rowe of Liverpool's Collective Encounters who worries "about traditional modes of AD getting set in stone. It's an artistic process that needs to be interrogated." (Cavallo \& Fryer, 2018, p. 38).

\subsection{Integrated $A D$}

Integrated $A D$ (IAD) comprises the opposite characteristics (Fryer, 2018) having evolved in response to the perceived deficits of TAD outlined above. It is conceived from the start of the creative process with the full support and involvement of the artistic team (Cavallo \& Fryer, 2018). Citing Cavallo, Fryer (2018) suggests that IAD should be considered less as a neutral way of conveying the source text and more as a creative tool, with the aim of "connecting both audience and performer to each other and the artistic content of a piece in a positive way" (Cavallo, 2015, p. 133).

This was the approach taken by Graeae, who describe themselves as "pioneers [of] a radical dramatic language by exploring the 'aesthetics of access', creatively embedding a range of tools such as audio description and sign language from the very beginning of the artistic process" (Graeae.org, n.d.). For example, Graeae's wheelchair dancing troupe, the Rhinestone Rollers features an able-bodied caller, whose character name is Studley Dudley. Like the dancers, he wears line-dancing gear, in his case denims, a rhinestone-studded belt and a Stetson. He is very much part of the act. $\mathrm{He}$ is also an audio describer (Willie Elliott) who like many other describers turned to description after or in tandem with a career in acting". By "calling" the dance moves Studley keeps blind, as well as sighted members of the audience and indeed members of the cast, up to speed with what is going on. It is $A D$ but in a style that is so utterly in keeping with the performance that the sighted audience is unaware that they are listening to AD.

\subsection{Strategies of Integration}

The describer-as-character approach, embodied by Studley Dudley, took the form of adding descriptive lines for a pre-existing character in the Canadian production of Shakespeare's Hamlet (Udo \& Fels, 2009) mentioned above. This shows that IAD is neither limited to the UK nor suitable only for newly-devised performances but can also be used for pre-existing plays. This strategy was also adopted for a 2018 production by Ramps on the Moon of Timberlake Wertenbaker's play Our Country's Good (1998). By contrast Fingersmiths' 2018 tour of John Godber's comedy Up ' $n$ ' Under (1984) inserted the describer as a supplementary character (a sports commentator) in keeping with, rather than integral to the text. In this production, the AD was still closed so that AD users listened to it via a headset, even though the describer-as-character was in full view. Describer Willie Elliott (Cavallo \& Fryer 2018, p. 35) explains the practical implications of describing from the stage:

Because it's all about rugby there's a conceit that I'm a sports commentator so I already have a big headset with a mic taped inside it - a radio mic - and in one of my pockets I've got 
a transmitter with a mute switch so that's on and off and on and off all through the show. And even at one point when I'm commentating with a handheld microphone in one hand to the whole audience I take it away and switch on my audio description in my pocket and I'm back and forth so it's quite complicated; it is a bit like patting your head and rubbing your stomach "I. And at the end of the piece there is a rugby match. The writer John Godber was very detailed about what happens in the match, so l've been able to lift that and use it as commentary and just change little bits to make it in the present and change the style of the writing, so it becomes, you know-sports commentary rather than just stage directions. It is very detailed and the director has used that detail to choreograph the game. So for me it has just been a case of lifting it out.

Maria Oshodi, CEO of Extant outlines a range of ways AD has been integrated into their productions, some of them non-verbal:

We've integrated access and audio description into scripts, so we've worked when we've been creating drafts of scripts to have an awareness that things might need to be described. IV We have done it with sound designs that reflect the lighting designs, so if we have a mood that changes in the lighting we reflect that in the sound. It's not described as such, but it creates a sense of the atmosphere through the sound. We've done it through performers describing themselves, through performers describing other performers, so it's either first or second person. We've done it (through) call and response with audiences and [...] enlisted the audience to join in to find ways of describing things. (Cavallo \& Fryer, 2018, p. 36)

Oshodi shows that one strategy used in IAD is changing the tense of the description, abandoning the injunction to describe in the third person - a tense that gives an illusion of neutrality. Without reopening the subjective/objective debate, suffice it to point out that as Cavallo (2015) notes when describing herself in her role in the Extant show Burlesque "Just the simple act of putting the $A D$ into first person speech suddenly gave it a new sense of power and control." (p. 127). A variety of tenses were used in Moon, a dance/circus piece for children based on a story by Hans Christian Andersen. The AD was created by the author with 2Faced Dance, a company based in Hereford, UK. In this instance the AD was written by the describer with input from the dancers from the perspective of the Moon, who swung in an aerial hoop above the performance space for most of the show. The Moon was already scripted to speak directly to the audience at the start of the work and to exchange words with the young boy he befriends, so this was continued in the description which was created towards the end of the rehearsal process. At times the Moon directs the boy, at others he reflects on the boy's actions in the form of a running commentary. As children often use this type of self-narrative, describing what they are doing as they are playing, it was considered in keeping with the piece, as well as assisting anyone in the audience who might find it difficult to observe the action directly. A short excerpt is given below (Example 1). 
It includes some vocabulary options so that the dancer could choose whichever term he felt best suited either his own way of speaking or that of his character.

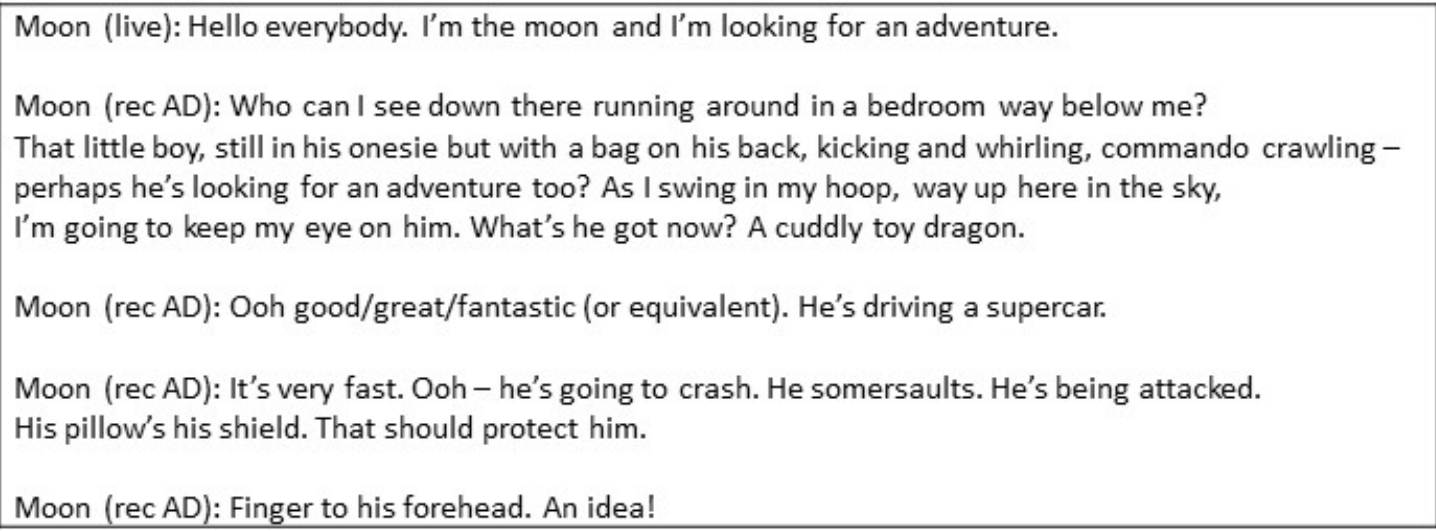

Example 1. Excerpt from Moon.

The $A D$ was voiced by the dancer playing the Moon, recorded and mixed into the soundtrack. This was to improve audibility for outdoor performances and to save the breath of the dancer for his physical feats.

\section{Access and Power}

It is no accident that disabled-led companies such as Graeae and Fingersmiths have been leading the way in IAD, as it is in the spirit of "Nothing about us, without us" which was the rallying call of people with mental and physical disabilities in South Africa in the 1980s and 1990s (Rowland, 2004).

Jenny Sealey, who is deaf, is explicit about the desire to regain artistic control over practices that have traditionally been delegated to access professionals:

That was the beginning of Graeae's journey of exploring how you might use $A D$ as an artistic tool, access as well, but something that was led by the art in the same way that sign language was informed by the art. It also meant we could have more control over it. (Cavallo \& Fryer, 2018, p. 45)

From a user perspective, Cavallo complains that TAD dictates the interpretation of how visual information should be perceived "regardless of where those receiving the service wish to place their focus" (2015, p. 127). She adds that TAD "tightly controls what information is considered important and what is deemed irrelevant". These concerns about control chime with the ideas of Gal \& Irvine (1995, p. 995) who argue that "there is no view from nowhere, no gaze that is not positioned." 


\subsection{Power in Translation}

Access practices such as $A D$, subtitling and signing have long been recognised as forms of translation (e.g., Díaz Cintas \& Anderman 2008). Fawcett (1995) suggests that "translation in all its forms is frequently the site of a variety of power plays between the actors involved" (p. 177). As Szarkowska (2005, section 3) puts it "translation is often seen as a form of conquest." Access practices in the UK, and arguably latterly in Europe, grew up as a result of the supreme power, the state or super state, placing legal obligations on service providers to make reasonable adjustments to make their services accessible (European Accessibility Act, forthcoming; UN Committee on the Rights of Persons with Disabilities, 2014; UK Equality Act, 2010). The concerns about TAD and the development of IAD show that there are more stakeholders in AD from a power perspective than simply users and describers. Fryer (2019) lists eight stakeholders with respect to $A D$ quality:

- $A D$ users; the performance venue;

- the law;

- the venue's funders;

- the description agency;

- the describer (student or professional);

- ADLAB PRO (or any course provider);

- the source text (ST) creator(s).

For the current working practices of theatre describers, and by extension for describer training, the most significant from this list are the ST creators i.e. members of the artistic team, who as demonstrated above are taking an increasing interest in how they and/or their work is described.

\subsection{Enhanced $A D$, Power and partiality}

As stated above, one type of power that the translator wields is the ability to decide which part of a text to emphasise. Tymoczko (2000) calls this partiality arguing that for literary translations, this is "often demonstrable in the paratextual materials that surround translations, including introductions, footnotes, reviews, literary criticism and so forth" (Tymoczko, 2000, p. 24). Both TAD and IAD can be partial in this sense as they expand the ST by adding what Extant refers to as enhanced $A D$ with the addition of audio introductions (Als) and touch tours (ToTos) (Fortnum \& Hall, 2016). Extant's research demonstrates that these are the aspects that can be provided by the company relatively cheaply, with or without direct involvement of audio describers. They are also highly appreciated by AD users (Eardley-Weaver, 2014; Fortnum \& Hall, 2016). However, Honig (1997, p. 15) believes that "the more a translator explains text, the less s/he can hope for a user response which is even remotely similar to that of the ST [source text] 
user." While both IAD and TAD add to the ST in this way, IAD goes further in actively altering the ST, as in the types of integration outlined above. Yet this type of interaction between the AD and the ST is not necessarily negative. For his hip hop dance company, Rationale, Nathan Geering explains how he might extend a sequence of dance moves to give the describer enough time to explain what is happening. He describes $A D$ as "a key factor in determining our choreography" (Cavallo \& Fryer, 2018, p. 35). Is this a case of the tail wagging the dog? Or is it a pragmatic response to easing the timing constraints of TAD? The answer to that depends on the status accorded the ST.

\section{Abusive Translation}

It might be argued that TAD evolved to avoid transforming the ST in a manner considered to be abusive (Nornes, 1999). Nornes was elaborating ideas advanced by Philip E. Lewis (1985) in his analysis of inherent differences between the languages of English and French. Lewis was frustrated by the "tendency for the translation of essayistic texts to concentrate on meaning to the exclusion of texture and materiality" (cited in Nornes 1999, p. 18). Discussing AVT (audiovisual translation) Nornes argues that subtitles are abusive because they violently transform the ST. What the user receives is not a version of the original, Nornes suggests but "an experience of translation" (1999, p.18). As there is no way around this, he suggests the best approach is to embrace it, aiming for a "strong, forceful translation that values experimentation, tampers with usage, seeks to match the polyvalencies or plurivocities or expressive stresses of the original by producing its own." (Lewis, 1985, p. 16) This is certainly the approach taken by IAD whereby access is seen "as a catalyst for creativity" (Cavallo, 2015 , p. 126). Given that parts of the original can only be accessed by AD users via the translation, $I A D$ aims to make that translation as engaging, stimulating or enjoyable as is the original for those who can access it directly. This marks a step change from regarding the original as sacred and not to be tampered with, to regarding the original as setting the standard and type of experience to be achieved.

\subsection{Suppression}

For subtitling, given the impossibility of reproducing every line of dialogue verbatim, Nornes sees one of its greatest abuses as suppression, whereby the translator decides words to leave out. For TAD, that same power is currently concentrated in the hands of the describers who do not "say what they see" but say what they have the vocabulary for, what they notice, or what they have time to mention. In the author's experience service providers in the form of venues and producers are increasingly monitoring (with the intention of suppressing) how the describer chooses to describe characters, especially with regards to physical characteristics including age, build, skin-colour and ethnicity. This is returned to below. 


\subsection{Epochs of translation}

The transition from describer-led to artist-led description could be seen as inevitable; certainly it travels a well-trodden path. Nornes (1999) uses the example of Japanese subtitles to outline three eras of translation. He posits "the first era of subtitles brings the foreign text to the spectators on their own domestic terms" (p. 28). In the second era:

The translator pretends to move toward the foreign, dwell there, and bring its wonders to the waiting crowds. This era is replete with rules designed to guarantee a translation's quality, but what this regulation accomplishes is an appropriation of the source text and its thorough domestication. The rules also enforce a territorialisation and professionalization of translation, producing stars and experts and excluding all alternatives (pp. 28-29).

The concerns of the theatre makers and $A D$ users interviewed for the Integrated Access Inquiry (Cavallo \& Fryer, 2018) show that it is in this second epoch that TAD is perceived to reside. This for Nornes, is the corrupt mode of translation, because

These (translators) claim to bring their...spectators to a pleasurable experience of the foreign, but in fact they please only themselves through these impoverished translations. As for their audiences, they are kept ignorant of the conspiracy and the riches that remain hidden from the [...] experience (1999, p. 29).

Nornes goes on to identify a third epoch, a golden age:

In the third epoch ... this translation does not present a foreign divested of its otherness but strives to translate from and within the place of the other by an inventive approach to language use and the steady refusal of rules (1999, p. 29).

This is where IAD is to be found with its emphasis on creative approaches developed in collaboration with the artistic team. In a reference to the traditional benshi whose job was to explain foreign films to Japanese audiences, Nornes cites Tatsuo $(1939$, p.51) about subtitling in Japan:

Subtitlers must strive to be like the benshi, which is to say become one with the fabric of the film, so they may speak directly to their audience in the deepest sense... Above all, their subtitles should not be direct translations of foreign words, but strive for a perfect match with the Japanese soul." (Nornes, 1999, p. 27).

It could be argued that as part of the fabric of the production, integrated AD becomes one with the ST and not separate from it, such that any alteration cannot be seen as abusive. This is the attitude taken by the small companies mentioned above. Yet IAD is not limited to small 
companies. The New Wolsey Theatre is a mid-scale touring venue in Ipswich, UK. Sarah Holmes, its chief executive, agrees that $A D$ should be seen as simply another creative tool for directors to use. She exhorts directors to:

get excited about the addition that you're getting to your... I call it the palette. A creative team has a palette to work from and they've got very good at sets and costumes and lighting and then they introduced audio visual projection. That was a new thing in the palette. When you think about [AD] as one of those - it's something else for you to work with." (Cavallo \& Fryer, 2018, p. 45).

If IAD also meets the needs of people with sight loss better than TAD, it is to be welcomed as perhaps an inevitable part of the evolution of translation.

\section{AD and User Needs}

Qualitative interviews with artistic directors suggest that fulfilling user needs by providing access is their primary motivation (Cavallo \& Fryer, 2018). For example, Sarah Holmes explains that integrated access for her company means her theatre "taking its responsibility seriously to create opportunity for everyone." (Cavallo \& Fryer, 2018, p. 12). While Nathan Geering says, "Integrated access is literally just about making sure that everybody has an equal opportunity to experience our productions" (Cavallo \& Fryer, 2018, p. 12). If everyone agrees about the primary purpose of $A D$, what remains contentious is the best way in which those needs can be met. While the perceived shortcomings of TAD have been made clear, there is a danger that integrated approaches risk prioritising art over access (Cavallo \& Fryer, 2018). In other words, the access baby risks being thrown out with the artistic bathwater.

\subsection{Describer Skills and Competences}

In IAD, it is the role of the describer to preserve the access element using their knowledge of the needs of People with Sight Loss (PSL). Current AD teaching has been found to be inclusive in that many trainers involve PSL in the training process and the majority of courses "also focus on accessibility issues and making students aware of the needs of the visually impaired" (ADLAB PRO, 2017a, p.34). Extant's research suggests that venues and producers respect this aspect of describer expertise, together with describers' understanding of how the AD fits around the ST. One venue experimented with making the TAD available for every performance by recording it. While the arguments for and against recording AD for live events is beyond the scope of this article, they found that members of the technical crew not trained in $A D$ found it hard to get a feel for its requirements: 
David (New Wolsey Theatre): ...our DSM (Deputy Stage Manager) as well as cueing lights and sound and everything else [...] had to also cue the AD. And the feedback from them was [...] they didn't feel a cue. They can kinda feel there's a lighting cue, they can feel when the scene changes happen [...] but for AD cues it is very strange. She almost didn't quite understand or have feeling for what was going so...

Sarah $\mathrm{H}$ (New Wolsey Theatre): So that's when we got our first professional AD team in (Cavallo \& Fryer 2018, p. 32).

\subsection{Describer Profile and Expertise}

As argued above, TAD, situated in the second epoch of translation, is perceived to be rule-bound. Nornes points out that "the rules also enforce a territorialisation and professionalization of translation, producing stars and experts and excluding all alternatives" (Nornes, 1999, pp. 28-29). So who are the describers that star in TAD? Finding the answer to that question has been the focus of the second intellectual output of $A D L A B$ PRO, the PRO being short for profile definition. According to the report put together by Elisa Perego and her team at the University of Trieste (ADLAB PRO, 2017b), up until now "little is known about who audio describers are, and there is no clear knowledge on whether and how they received training and how training is organized" (2017b, p. 1). To that end, ADLAB PRO circulated a questionnaire (IO2) that was completed by 183 participants: 65 describers, $100 \mathrm{AD}$ users and 18 service providers. Perego concludes that "the majority of audio describers are professional, trained and paid workers" (ADLAB PRO, 2017b, 2.3.1) prized for their "world knowledge" as well as for their knowledge of: the target audience; AD principles, guidelines and standards; language and linguistics; media accessibility; scriptwriting; audio visual texts and multimodality (listed in order of importance) (ADLAB PRO, 2017b, 4.2).

The particular competences that the professional, trained describers could supply to the New Wolsey Theatre in the example above are referred to in the IO1 report as the "technical aspects" of AD. They comprise editing, timing and text compression and are ranked fourth in importance of specific $A D$ competences by 86 existing teachers and trainers (ADLAB PRO, 2017a, p. 6). Top of the list was content selection i.e. "choosing the most relevant information to describe" (ADLAB PRO, 2017a, p. 6).

\subsection{Accuracy, Freedom and the Describer}

Scholars have noted that what is chosen will vary according to the function of the ST (e.g. Matamala \& Remael, 2015). Vermeer (1989) suggests it is up to the translator to decide the function of the text but that the best translator will make that decision in consultation with the client. Compared with TAD, IAD shifts the weight of that responsibility from the translator (describer) to the ST creators. The artistic team is more likely to be the direct client in IAD, 
than in TAD where the describer is likely to be employed by the venue, either directly or via an agency.

\subsection{Describer Training}

The current model of describer training encourages describers to see themselves as independent decision makers. For example, The ADLAB Guidelines (Remael, Reviers \& Vercauteren, 2015) urge the describer to "determine" 89 times and "decide" 102 times as well as "choose" 7 times. In an era of IAD, training should make students aware that the language of their description will be created with input from the company or the ST creators, who may monitor the register of the AD so that it echoes more closely the register of the piece and reflects the sensitivities of the company's worldview i.e. the source culture. The responsibility for language choice will not lie solely on the describer's shoulders suggesting that soft skills such as teamwork, which is currently ranked 7th in terms of importance (ADLAB PRO 2017a, p.30), would benefit from a greater emphasis in training. The ADLAB guidelines currently indicate collaboration with "audio describers, voice talents or voice actors, sound technicians and users" (Remael et al., 2015, section 1). This list should be expanded to embrace members of the artistic team, in particular the director (Naraine, Whitfield \& Fels, 2017). ADLAB PRO's survey of current training provision (2017a) also found that soft skills such as self-development were rated as slightly more important than teamwork. This balance should shift in future courses in recognition of AFM and IAD.

The danger posed by the prioritisation of artistic concerns over access means that the describer might need to battle for the rights of the AD users, particularly in the light of pressure for language to be made more politically correct (PC) mentioned above. Marques defines "political correctness" as the avoidance of "all expressions or actions that could possibly be perceived to exclude, marginalise or insult people who are socially disadvantaged or discriminated against" (2009, p. 257). Excluding "sensitive" details about body-shape, skin-colour, age and ethnicity risks reducing the amount of descriptive information available to PSL compared with what is visible to the sighted audience. Describers and providers were asked to rate the importance that describers be assertive in fighting for the quality of $A D$ provision. Describers ranked it fourth in terms of importance, compared with service providers who only ranked it 8th (ADLAB PRO, 2017b, p. 30). This imbalance suggests that describers play an advocacy role that has not yet been recognised.

\subsection{AD Workflow}

Another impact on practice and training comes in workflow. Writing a description already takes place over a longer timespan for the $A D$ of live events compared with screen $A D$. This is extended even further in IAD by involving describers in the planning stage and the rehearsal process. Thus, IAD avoids the criticism encountered by other modes of AVT as expressed by Romero-Fresco \& Fryer (2018) advocating for AFM strategies. Currently, as they point out "translation and accessibility 
are relegated to the distribution stage of the filmmaking process and outsourced to translators who work with tight deadlines, small remuneration and no access to the creative team" (p.12). By moving accessibility into the development stage of the process, all of this changes, as translators can influence the timeline and possibly the budget. Certainly, they can help the creative team think about these things in advance, taking on some of the role given to the Director of Accessibility and Translation that has been proposed for AFM (Branson, 2017).

Another conclusion of the IAI is that "The best access is tailor-made for each show. This includes casting an appropriate access professional." (Cavallo \& Fryer, 2018, p. 10). Furthermore, there is concern that "the current pool of describers is not sufficiently diverse" (Cavallo \& Fryer, 2018, p. 10). Nathan Geering clarifies that "generally audio describers seem to be in their 40s 50 s and $60 \mathrm{~s}$ " (Cavallo \& Fryer, 2018, p. 39). This is likely to reflect the situation in the UK, where description has been practiced since the mid-1990s (Fryer, 2016), rather than being more broadly applicable. However, it would nonetheless suggest that initiatives such as ADLAB PRO are more necessary than ever. The training should also incorporate information about alternative ways of working. This might include being aware of the current guidelines so that describers understand what "rules" they are breaking and why.

In addition the background and existing skillset of potential candidates might need to be reconsidered. Currently ADLAB PRO (forthcoming) recommends that potential students already possess the following competencies:

- Linguistic and textual skills (this includes, for instance, a perfect use of the mother tongue, a command of style figures like metaphors and similes, the ability to use language that sparks the imagination, write a coherent text etc.).

- Vocal skills: A clear and pleasant reading voice is required for some modules;

- Transferrable skills/soft skills not specific to AD: efficient work organisation and time management, ethics, self-development, teamwork, problem solving, communicative and interpersonal skills, the ability to cope with time pressure, knowing when and being willing to call for expert or peer help, dealing with feedback and working to a deadline.

- Computer skills: database management, word processor, etc.

The evolution of IAD suggests that performance experience would be of huge benefit for students training to describe live events. This would give more companies the option of placing the describeras-character on stage. 


\section{Conclusion}

The title of this article suggests that while the appetite for $A D$ is strong, the role of the describer is changing. No longer is the describer autonomous and left to their own devices, with the power to decide on the purpose and style of their translation, aiming for neutrality, taking guidelines into account. Instead, the description is one more creative aspect of the product, to be determined by the creative team with the impact on user experience uppermost in their minds. The expertise of the describer is recognised in terms of knowledge of their audience and selecting from the range of visual information available. Describer skills and competencies are still required as $A D$ transitions into this third epoch.

\section{Acknowledgements}

This research was supported by the Erasmus+ Programme of the European Union: Project name ADLAB PRO; Project number: 2016-1-IT02-KA203-024311.

The information and views set out in this chapter are those of the author and do not necessarily reflect the official opinion of the European Union. Neither the European Union institutions and bodies nor any person acting on their behalf may be held responsible for the use which may be made of the information contained therein.

\section{Biographical note}

Louise Fryer, PhD, was the BBC's describer for the pilot TV Audio Description Service (AUDETEL), the accessibility advisor for the film Notes on Blindness (2016) and helps develop integrated access for film and live performance. She describes for the UK's National Theatre and VocalEyes. She is a Senior Teaching Fellow at University College, London (UCL) and wrote An Introduction to Audio Description: A Practical Guide (2016) London: Routledge. Through her company, Utopian Voices Ltd. she is a partner in ADLAB PRO.

\section{References}

ADLAB PRO (2017a). Report on 101: Audio description professional: Profile definition. Retrieved from http://www.adlabpro.eu/wp-content/uploads/2017/12/20170608 uam io1 report.pdf

ADLAB PRO (2017b). Report on 102: Audio description professional: Profile definition. Retrieved from https://www.adlabpro.eu/wp-content/uploads/2018/04/IO2-REPORT-Final.pdf

ADLAB PRO (forthcoming). Report on I03: Course Design.

Branson, J. (2017, September). Bringing media accessibility in from the cold: a comparative analysis of collaborative and standard approaches to AD and SDH. Paper presented at Media 
Accessibility Platform International Conference, Vigo, Spain.

Cavallo, A. (2015). Seeing the word, hearing the image: the artistic possibilities of audio description in theatrical performance. Research in Drama Education: The Journal of Applied Theatre and Performance, 20(1), 125-134.

Cavallo, A. \& Fryer, L. (2018). Integrated access inquiry 2017-18 report. Retrieved from https://www.extant.org.uk/docs/uploads/Extant Integrated Access Report 2018 Full Len gth.docx

Connell, B. R., Jones, M., Mace, R., Mullick, A., Ostroff, E., Sanford, J., Steinfeld, E., Story, M., \& Vanderheiden, G. G. (1997, April 1). The principles of universal design. Retrieved from https://projects.ncsu.edu/design/cud/about ud/udprinciplestext.htm

Díaz Cintas, J., \& Anderman, G. (Eds.). (2008). Audiovisual translation: Language transfer on screen. Basingstoke: Palgrave Macmillan.

Eardley-Weaver, S. (2014). Lifting the curtain on opera translation and accessibility. Translating opera for audiences with varying sensory ability (Unpublished doctoral dissertation). Durham University, Durham, UK. (School of Modern Languages and Cultures).

Fawcett, P. E. (1995). Translation and power play. The Translator, 1(2), 177-192.

Fortnum, J., \& Hall, C. (2016). The chairs tour project evaluation report. Retrieved from http://extant.org.uk/news/audience agency the results are in

Fryer, L. (2019). Quality assessment in audio description: lessons learned from interpreting. In E. Huertas-Barros, S. Vandepitte \& E. Iglesias-Fernández (Eds.), Quality assurance and assessment practices in translation and interpreting (pp. 155-177). IGI Global.

Fryer, L. (2018). Staging the audio describer. Disability Studies Quarterly, 38(3). Retrieved from http://dsq-sds.org/article/view/6490/5093

Fryer, L. (2016). An introduction to audio description: A practical guide. London: Routledge.

Fryer, L. \& Freeman, J. (2014). Can you feel what I'm saying? The impact of verbal information on emotion elicitation and presence in people with a visual impairment. In A. Felnhofer \& O. D. Kothgassner (Eds.), Challenging presence: Proceedings of the 15th international conference on presence (pp. 99-107). Vienna: facultas.wuv.

Gal, S., \& Irvine, J. T. (1995). The boundaries of languages and disciplines: How ideologies construct difference. Social Research, 62(4), 967-1001.

Godber, J. (1984). Up ' $n$ ' under. London: Samuel French Ltd.

Graeae.org. (n.d.). Access. Retrieved from http://graeae.org/about/access/

Greco, G. M. (2016). On accessibility as a human right, with an application to media accessibility. In P. Oreo \& A. Matamala (Eds.), Researching audio description (pp. 11-33). London: Palgrave Macmillan.

Honig, H. G. (1997). Positions, power and practice: functionalist approaches and translation quality assessment. Current Issues in Language \& Society, 4(1), 6-34.

Ionesco, E. (1958). The chairs. The bald soprano and other plays. (D. M. Allen, Trans.). New York: Grove Press.

Lewis, P. E. (1985). The measure of translation effects. In J. F. Graham (Ed.), Difference in translation (pp. 31-62). Ithaca, NY: Cornell University Press. 
Lopez, M. J., Kearney, G. C., \& Hofstadter, K. (2018). Audio description in the UK: what works, what doesn't and understanding the need for personalising access. British Journal of Visual Impairment, 36(3), 274-291.

Marques, J. F. (2009). How politically correct is political correctness? A SWOT analysis of this phenomenon. Business \& Society, 48(2), 257-266.

Matamala, A. \& Remael, A. (2015). Audio-description reloaded: an analysis of visual scenes in 2012 and Hero. Translation Studies, 8(1), 63-81.

Naraine, M. D., Whitfield, M. R., \& Fels, D. I. (2018). Who's devising your theatre experience? A director's approach to inclusive theatre for blind and low vision theatregoers. Visual Communication, 17(1), 113-133.

Nornes, A. M. (1999). For an abusive subtitling. Film Quarterly, 52(3), 17-34.

Ramos, M. (2015). The emotional experience of films: does audio description make a difference? The Translator, 21(1), 68-94.

Remael, A., Reviers, N. \& Vercauteren, G. (2015). Pictures painted in words: ADLAB Audio Description guidelines. Trieste: EUT.

Romero-Fresco, P. \& Fryer, L. (2018). Accessible filmmaking guide. London: British Film Institute.

Rowland, W. (2004) Nothing about us without us: Inside the disabilities rights movement of South Africa. Pretoria: Unisa Press.

Shakespeare, W. (2005). Hamlet. Retrieved from http://Shakespeare,mit.edu/hamlet/full.html

Szarkowska, A. (2005). The power of film translation. Translation Journal, 9(2). Retrieved from http://translationjournal.net/journal/32film.htm

Tatsuo, O. (1939). Supa Impozu ni Okeru Nihongo no Hinkon [The poverty of Japanese language of spoken titles]. Nihon Eiga, 4(5), 51.

Thompson, H. (2015, August 3). How the arts can help change attitudes to blindness. The Guardian. Retrieved from https://www.theguardian.com/culture-professionalsnetwork/2015/aug/03/arts-change-attitude-blindness-blind-creations

Tymoczko, M. (2000). Translation and political engagement: activism, social change and the role of translation in geopolitical shifts. The Translator, 6(1), 23-47.

Udo, J. P. \& Fels, D. (2009). Suit the action to the word, the word to the action: an unconventional approach to describing Shakespeare's Hamlet. Journal of Visual Impairment \& Blindness, 103(3), 178-183.

Udo, J. P. \& Fels, D. (2010). The rogue poster-children of universal design: closed captioning and audio description. Journal of Engineering Design, 21(2-3), 207-221.

UN Committee on the Rights of Persons with Disabilities. (2014). General Comment No. 2, Article 9: Accessibility. Retrieved from http://daccessods.un.org/access.nsf/Get?Open\&DS=CRPD/C/GC/2\&Lang=E

Vermeer, H. J. (1989). Skopos and commission in translational action. In A. Chesterman (Ed.), Readings in translation theory (pp. 173-87). Helsinki: Oy Finn Lectura Ab.

Wertenbaker, T. (1998). Our Country's Good. Methuen Drama. Bloomsbury. London. 
' For a further discussion of AD and UD see Udo \& Fels (2010).

" Of the 65 describers who responded to a questionnaire circulated by ADLAB PRO (IO1, 2017), more than 10 $(15 \%)$ reported having been to acting school or included theatre studies in their educational background (multiple answers were possible).

II' An abbreviation of an English idiomatic expression referring to two things that are hard to do simultaneously.

${ }^{\text {IV }}$ An ellipsis [...] has been introduced where repetition or an irrelevant word or comment has been cut from the transcription, in the manner of an edited radio interview. 